\title{
THE THEORY OF SEXUAL SELECTION
}

\author{
P. O'DONALD \\ Department of Genetics, University of Cambridge
}

\section{INTRODUCTION}

Received 19.v.62

IN many groups of the animal kingdom, but especially amongst the birds, spectacular differences exist between the sexes. The distinction between the cock and hen pheasant or the mallard drake and duck are immediate and familiar examples. Darwin (1859 and I87I) put forward a theory to account for the evolution of these striking differences. This theory involves competition within the sexes, which Darwin called Sexual Selection. Thus, according to Darwin (1871), when " the males have acquired their present structure, not from being fitter to survive in the struggle for existence, but from having gained an advantage over other males, and from having transmitted this advantage to their male offspring alone, sexual selection must here have come into action."

Since its publication this theory has often been under attack. Thus in recent times Huxley (1938) has said: "display may often be of advantage to the species in promoting more effective reproduction. Any resultant selection will therefore come under the head of Natural Selection, not Sexual Selection in Darwin's sense." Thus Huxley cites evidence that display in birds, in addition to the psychological effects assumed by Darwin, may have important physiological effects such as the increasing of the effectiveness of ovulation, the earlier maturing of the gonads, or the synchronisation of the male and female rhythms. These physiological effects must, however, be considered as the product of some selective process, rather than as something given. Females stimulated by the display of the more highly endowed males must clearly gain an advantage so long as the sons of these males retain an advantage in sexual selection. Sexual selection may well therefore enhance the effects of natural selection.

Cott (1954) has also argued that many of the differences between the sexes are the result of natural selection. "In sexually dimorphic game birds, ducks and others which nest in the open, it is typically the male that has utilised the biological advantages of conspicuousness, whether for purposes of display or distraction; while the female, upon whom devolves the duty of incubation, has been forced to take the evolutionary road to concealment." Darwin himself had in fact made precisely this point: "When the two sexes differ in structure in relation to different habits of life, they have no doubt been modified through natural selection, and by inheritance limited to one and the 
same sex." Mottram (19I5), by tabulating species which did or did not manifest differences between the sexes, has made the interesting observation that species liable to attack by predators more often have sexually dimorphic characters than fierce, large or sociable birds. Thus he found that sexual dimorphism is more common in species lacking offensive weapons than in well-armed birds; that edible species (according that is to man's palate) show more examples of sexual differences than others; that large species are less often sexually dimorphic than small; and that the same is true of sociable or colonial birds. Thus the fierce and colonial Arctic skua, which in the breeding season almost appears to regard man as legitimate prey, cannot be separated into the two sexes in the field. Mottram's data thus appear to support the view that differences between the sexes have arisen by natural, not sexual selection.

The type of selection supposed by Cott to operate in these cases is that now commonly called disruptive. Mather (1 955) has analysed the action of selection into three components: stabilising selection, which operates against the more extreme deviants in a population; directional selection, which leads to a change in the population mean; and disruptive selection. Disruptive selection arises when several different optima are favoured in the environment. Mather has argued that disruptive selection may give rise under certain conditions to a stable polymorphism; but the population exposed to the divergent selective pressures must be held together by some tie in which the various favoured phenotypes form an integral part of the others' environment. In Cott's argument the different optima favoured are represented by a well-concealed female incubating the eggs, and a conspicuous male whose display will lead to the greatest possible stimulation of the female and whose distraction behaviour depending partially at least upon his conspicuousness will lure predators away from the nest. Here it is the co-operation between the sexes which forms, of course, the essential tie between two groups upon which the different selective pressures are operating: were such a tie not present, disruptive selection must lead to the ultimate independence of the two groups. The segregation of the sex chromosomes acts as the switching system to canalise the development into the male or female forms.

Maynard-Smith (1958) has suggested that sexual selection might be expected to produce a rather different result from the effects evolved under natural selection. If sexual display acts as a "signal" to evoke the appropriate response from the partner, these displays may be regarded as analogous to notices giving information like "London" or "Brighton", and different from advertisements, which the effects of sexual selection might be expected to resemble. He, therefore, thinks that sexual selection must indeed have played a large part in the evolution of sexual differences which are so often of a showy and spectacular nature. 
In spite of these continued disagreements on the importance of sexual selection, Fisher (1930) had already provided the basis for the discussion of the origin of the sexual preference of the female, upon which the action of sexual selection must depend. "Whenever appreciable differences exist in a species, which are in fact correlated with selective advantage, there will be a tendency to select also those individuals of the opposite sex which most clearly discriminate the difference to be observed, and which most decidedly prefer the more advantageous type." Thus in Fisher's theory, the evolution of the striking sexual dimorphism of many birds occurs under the action of two forms of selection. There will be an initial advantage depending on disruptive selection between the opposing advantages in the two sexes of conspicuousness and concealment, or as a result of selection for sex-recognition and display: females mating with the more extreme males, whose greater conspicuousness shall we say gives them an advantage, will thus contribute a greater proportion of ancestry to future generations than those mating with the males whose characters are nearer the population mean. Females with an hereditary preference for such matings must therefore increase in the population. A similar argument might be applied to the evolution of male choice: those males preferring the best concealed females must also be supposed to possess a selective advantage. The intensity, for example of the female preference, must then continue to increase so long as the sons of the females exercising their preference continue to gain an advantage either from the advantage they possess in disruptive selection, or from the advantage due to female preference. Fisher suggests that the characters which have thus gained a selective advantage will be further developed beyond the point at which their advantage in disruptive selection has ceased. Fisher's argument shows how the "advertisements" in Maynard-Smith's analogy have evolved from the " notices" designed only to convey information.

\section{MATHEMATICAL MODELS OF SEXUAL SELECTION}

The models we shall discuss are based on the assumption that in a diallelic system the females select one of the three male genotypes. The males on the other hand are assumed to mate with any female offering herself.

Suppose that a proportion $\alpha$ of the females are prepared to mate only with males of genotype AA; the remaining $I-\alpha$ fraction of the females mate with the male genotypes $\mathrm{AA}, \mathrm{AB}$ and $\mathrm{BB}$ at random. Sexual selection is thus acting in favour of the AA males, for some females will only offer themselves to these males who will also have a chance of mating with the randomly mating females. The male character determined by the alleles $\mathrm{A}$ and $\mathrm{B}$ will of course be passed on by the females even though they themselves do not show it. Thus if $u, v$ and $w$ are the frequencies of the genotypes AA, 
$\mathrm{AB}$ and $\mathrm{BB}$, the six possible mating types will have the following frequencies.

$$
\begin{aligned}
& \text { Mating Type } \\
& \mathrm{AA} \times \mathrm{AA} \\
& \mathrm{AA} \times \mathrm{AB} \\
& \mathrm{AA} \times \mathrm{BB} \\
& \mathrm{AB} \times \mathrm{AB} \\
& \mathrm{AB} \times \mathrm{BB} \\
& \mathrm{BB} \times \mathrm{BB}
\end{aligned}
$$

If this system of mating preference were a characteristic of the whole population, so that $\alpha$ represented the probability that any female would show a preference for an AA male and that this probability was constant from generation to generation; then we should have a set of recurrence relations obtainable directly from the frequencies of the mating types. If $u, v$ and $w$ represent the genotypic frequencies in generation ' $n$ ', and $u^{\prime}, v^{\prime}$ and $w^{\prime}$ the corresponding frequencies in generation ' $n+\mathrm{r}$ ', we have

so that

$$
\begin{aligned}
u^{\prime} & =\alpha\left(u+\frac{1}{2} v\right)+(\mathrm{I}-\alpha)\left(u+\frac{1}{2} v\right)^{2} \\
v^{\prime} & =\alpha\left(w+\frac{1}{2} v\right)+2(\mathrm{I}-\alpha)\left(u+\frac{1}{2} v\right)\left(w+\frac{1}{2} v\right) \\
w^{\prime} & =(\mathrm{I}-\alpha)\left(w+\frac{1}{2} v\right)^{2},
\end{aligned}
$$

$$
p^{\prime}=\alpha p+\frac{1}{2} \alpha q+p(\mathrm{I}-\alpha)
$$

where $p$ and $q$ are the frequencies of the alleles $\mathrm{A}$ and $\mathrm{B}$ (i.e. $p=u+\frac{1}{2} v$, $\left.q=w+\frac{1}{2} v\right)$. This gives

$$
p^{\prime}=\left(\mathrm{I}-\frac{1}{2} \alpha\right) p+\frac{1}{2} \alpha
$$

or after $n$ generations starting at zero

Thus

$$
p_{n}=\left(\mathrm{I}-\frac{1}{2} \alpha\right)^{n} p_{0}+\frac{1}{2} \alpha\left[\left(\mathrm{I}-\frac{1}{2} \alpha\right)^{n-1}+\ldots+\left(\mathrm{I}-\frac{1}{2} \alpha\right)+\mathrm{I}\right]
$$

or

$$
p_{n}=\left(\mathrm{I}-\frac{1}{2} \alpha\right)^{n} p_{0}+\mathrm{I}-\left(\mathrm{I}-\frac{1}{2} \alpha\right)^{n},
$$

$$
p_{n}=\left(\mathrm{I}-\frac{1}{2} \alpha\right)^{n}\left(p_{0}-\mathrm{I}\right)+\mathrm{I} \text {. }
$$

Hence as $n \rightarrow \infty, p_{n} \rightarrow \mathrm{I}$ so long as $4>\alpha>0$, which must be so by hypothesis. Clearly selection must proceed very rapidly under this system whenever $\alpha$ is not very small.

This is the way in which Darwin considered sexual selection: every female is supposed to have some tendency towards a preference for a particular male adornment. Following Fisher, however, the sexual preference will itself be subject to selection: since in the next generation the sons with the genotype AA will be selected by those females exercising the sexual preference, then if the female preference is hereditarily determined it also will be selected; for the AA sons will be carrying a higher proportion of the genes which determine 
the sexual preference than will the other sons. To simplify the argument we shall consider the case of a sex-linked female preference, for in birds the female is heterogametic.

There are two cases to be considered: the gene for sexual preference may be linked either to the $\mathrm{Y}$ - or to the $\mathrm{X}$-chromosome. If the sexual preference is $\mathrm{Y}$-linked, then selection of the preference will not take place for the males do not carry the Y-chromosome. This is therefore a rather degenerate case; but we may not assume as we did in the model already described that the sexual preference will be distributed at random among the females. In fact the sexual preference will tend to become associated with the AA genotypes. It is clear that after the first generation any female having the sexual preference and carrying the genotype BB will disappear. Call the females having the sexual preference $\mathrm{XY}^{\alpha}$ and the rest $\mathrm{XY}^{+}$; then let the genotypic frequencies be as follows:

\section{Females}

$\begin{array}{lc}\text { Genotype } & \text { Frequency } \\ \text { AAXY }^{\alpha} & x \\ \text { ABXY }^{\alpha} & y \\ \text { BBXY }^{\alpha} & z \\ \text { AAXY }^{+} & r \\ \text { ABXY }^{+} & s \\ \text { BBXY }^{+} & t \\ \text { Total } & \text { I }\end{array}$

\section{Males}

$\begin{array}{cc}\text { Genotype } & \text { Frequency } \\ \mathrm{AA} & u \\ \mathrm{AB} & v \\ \mathrm{BB} & w \\ \text { Total } & \mathrm{I}\end{array}$

It can easily be shown that the gene frequency of the alleles A and B remains the same in both males and females. Thus

$$
\begin{aligned}
\alpha & =x+y \\
u & =x+r \\
v & =y+s \\
w & =t .
\end{aligned}
$$

The frequencies of the mating types will be as follows:

$$
\begin{aligned}
& \text { Mating Type } \\
& \mathrm{AA} \times \mathrm{AA} \\
& \mathrm{AA} \times \mathrm{AB} \\
& \mathrm{AA} \times \mathrm{BB} \\
& \mathrm{AB} \times \mathrm{AB} \\
& \mathrm{AB} \times \mathrm{BB} \\
& \mathrm{BB} \times \mathrm{BB}
\end{aligned}
$$

so that we have

$$
\begin{aligned}
& u^{\prime}=x+\frac{1}{2} y+\left(r+\frac{1}{2} s\right)\left(u+\frac{1}{2} v\right) \\
& v^{\prime}=\frac{1}{2} y+w\left(r+\frac{1}{2} s\right)+u\left(t+\frac{1}{2} s\right)+\frac{1}{2} v(r+s+t)
\end{aligned}
$$


or substituting for $r, s$ and $t$

Thus

$$
\begin{aligned}
& u^{\prime}=\left(x+\frac{1}{2} y\right)\left(w+\frac{1}{2} v\right)+\left(u+\frac{1}{2} v\right)^{2} \\
& v^{\prime}=-x\left(w+\frac{1}{2} v\right)+2\left(u+\frac{1}{2} v\right)\left(w+\frac{1}{2} v\right) .
\end{aligned}
$$

$$
p^{\prime}=\frac{1}{2} \alpha q+p=\left(1-\frac{1}{2} \alpha\right) p+\frac{1}{2} \alpha,
$$

which gives the same rate of selection as for the population in which every female has a constant probability of exercising the sexual preference. Hence

$$
p_{n}=\left(1-\frac{1}{2} \alpha\right)^{n}\left(p_{0}-1\right)+1 \text {. }
$$

As an example, suppose the initial frequencies were $\alpha=p_{0}=\frac{1}{2}$, then after five generations $p$ would have risen to 0.881 and after twenty generations to 0.998 . If the initial frequencies had been $\alpha=p_{0}=0.1$, $p$ after five generations would have become 0.304 , after twenty generations 0.678 and after fifty generations the frequency of the advantageous gene would have risen to 0.931 .

To examine how linkage might affect sexual selection we must assume that sexual preference $\alpha$ and the locus A-B are both situated on the X-chromosome. We shall assume that the two loci are closely linked so that crossing over is unlikely; the problem otherwise becomes mathematically intractable. Let the five genotypic frequencies be as follows:

$\begin{array}{lc}\text { Genotype } & \text { Frequency } \\ \mathrm{X}^{\alpha A \mathrm{Y}} & x \\ \mathrm{X}^{+B} \mathrm{Y} & y \\ \mathrm{X}^{\alpha A} \mathrm{X}^{\alpha A} & r \\ \mathrm{X}^{\alpha A} \mathrm{X}^{+B} & s \\ \mathrm{X}^{+B} \mathrm{X}^{+B} & t\end{array}$

where $x+y=\mathrm{I}$ and $r+s+t=\mathrm{I}$. The chromosome $\mathrm{X}^{\alpha A}$ carries the allele $\mathrm{A}$ and the gene determining the female preference for the AA males; $\mathrm{X}^{+B}$ carries the $B$ allele and the wild type at the female preference locus-such females mate at random. The four mating types will then have the following frequencies:

\begin{tabular}{rclc} 
Mating Type & Frequency & \multicolumn{1}{c}{ Female } & Offspring \\
$\mathrm{X}^{\alpha A} \mathrm{X}^{\alpha A} \times \mathrm{X}^{\alpha A} \mathrm{Y}$ & $x$ & $\mathrm{X}^{\alpha A} \mathrm{Y}$ & \multicolumn{1}{c}{ Male } \\
$\mathrm{X}^{\alpha A} \mathrm{X}^{\alpha A} \times \mathrm{X}^{+B} \mathrm{Y}$ & $r y$ & $\mathrm{X}^{\alpha A} \mathrm{Y}$ & $\mathrm{X}^{\alpha A} \mathrm{X}^{\alpha A}$ \\
$\mathrm{X}^{\alpha A} \mathrm{X}^{+B} \times \mathrm{X}^{+B} \mathrm{Y}$ & $s y$ & $\frac{1}{2} \mathrm{X}^{\alpha A} \mathrm{Y}+\frac{1}{2} \mathrm{X}^{+B} \mathrm{Y}$ & $\mathrm{X}^{\alpha A} \mathrm{X}^{+B}$ \\
$\mathrm{X}^{+B} \mathrm{X}^{+B} \times \mathrm{X}^{+B} \mathrm{Y}$ & $t y$ & $\mathrm{X}^{+B} \mathrm{Y}$ & $\mathrm{X}^{+B}+\frac{1}{2} \mathrm{X}^{+B} \mathrm{X}^{+B}$
\end{tabular}

In the following generation the frequencies of the genotypes will have become

\begin{tabular}{cc}
\multicolumn{2}{c}{ Females } \\
Genotype & Frequency \\
$\mathrm{X}^{\alpha A \mathrm{Y}}$ & $x+r y+\frac{1}{2} s y$ \\
$\mathrm{X}^{+B \mathrm{Y}}$ & $t y+\frac{1}{2} s y$
\end{tabular}

\begin{tabular}{cc}
\multicolumn{2}{c}{ Males } \\
Genotype & Frequency \\
$\mathrm{X}^{\alpha A} \mathrm{X}^{\alpha A}$ & $x$ \\
$\mathrm{X}^{\alpha A \mathrm{X}^{+B}}$ & $r y+\frac{1}{2} s y$ \\
$\mathrm{X}^{+B} \mathrm{X}^{+B}$ & $t y+\frac{1}{2} s y$
\end{tabular}


The gene frequency does not therefore remain the same in both males and females. Let the gene frequencies be $p_{f}+q_{f}=\mathrm{I}$ and $p_{m}+q_{m}=\mathrm{I}$ in females and in males respectively. Then we have

so that

$$
\begin{gathered}
x^{\prime}=x+y\left(r+\frac{1}{2} s\right) \\
r^{\prime}+\frac{1}{2} s^{\prime}=x+\frac{1}{2} y\left(r+\frac{1}{2} s\right)
\end{gathered}
$$

$$
\begin{gathered}
p_{f^{\prime}}=p_{f}+p_{m}\left(\mathrm{I}-p_{f}\right) \\
p_{m}^{\prime}=p_{f}+\frac{1}{2} p_{m}\left(\mathrm{I}-p_{f}\right) .
\end{gathered}
$$

These non-linear recurrence relations in two variables cannot be given an explicit mathematical solution. If, however, we assume that in an initial population the gene frequencies are $\left(p_{f}\right)_{0}=\left(p_{m}\right)_{0}=0 \cdot 1$, then in successive generations the gene frequencies will be

$\begin{array}{ccc}\text { Generation } & p_{f} & p_{m} \\ 0 & 0 \cdot 100 & 0.100 \\ 1 & 0.190 & 0.145 \\ 2 & 0.307 & 0.249 \\ 3 & 0.480 & 0.394 \\ 4 & 0.685 & 0.582 \\ 5 & 0.869 & 0.777 \\ 6 & 0.971 & 0.920 \\ 7 & 0.997 & 0.985\end{array}$

It is therefore clear that selection is extremely rapid. At equilibrium, when $p_{f}{ }^{\prime}=p_{f}$ and $p_{m}{ }^{\prime}=p_{m}$, we have

so that

$$
\begin{gathered}
p_{f}=p_{f}+p_{m}\left(\mathrm{I}-p_{f}\right) \\
p_{m}=p_{f}+\frac{1}{2} p_{m}\left(\mathrm{I}-p_{f}\right)
\end{gathered}
$$

or

$$
p_{m}\left(\mathrm{I}-p_{f}\right)=\mathrm{I}
$$

$$
p_{f}=\mathrm{I} \text {. }
$$

Thus $p_{f}=p_{m}=\mathrm{I}$, and equilibrium is reached when the advantageous gene has become fixed.

An expression for the initial rate of advance can be obtained by assuming that the term $p_{f} p_{m}$ is small and can be ignored. This gives

$$
\left(\begin{array}{l}
p_{f}^{\prime} \\
p_{m}{ }^{\prime}
\end{array}\right)=\left(\begin{array}{ll}
\mathrm{I} & \mathrm{I} \\
\mathrm{I} & \frac{1}{2}
\end{array}\right)\left(\begin{array}{l}
p_{f} \\
p_{m}
\end{array}\right)
$$

The latent roots are $\frac{3}{4}+\frac{1}{11} \sqrt{\mathrm{I} 7}$ and $\frac{3}{4}-\frac{1}{4} \sqrt{\mathrm{I} 7}$ or $1 \cdot 7808$ and -0.2808 and after $n$ generations, $p_{f}$ and $p_{m}$ still small, we have

$$
\begin{aligned}
\left(p_{f}\right)_{n}=(\mathrm{I} \cdot 7808)^{n}\left[(\mathrm{I} \cdot 2808)\left(p_{f}\right)_{0}+\left(p_{m}\right)_{0}\right]+ & (-0 \cdot 2808)^{n} \\
& \times\left[(0 \cdot 7808)\left(p_{f}\right)_{0}-\left(p_{m}\right)_{0}\right] \\
\left(p_{m}\right)_{n}=(\mathrm{I} \cdot 7808)^{n}\left[(0 \cdot 7808)\left(p_{m}\right)_{0}+\left(p_{f}\right)_{0}\right]+ & \left(-\frac{0 \cdot 2808)^{n}}{}\right. \\
\times & {\left[(\mathrm{I} \cdot 2808)\left(p_{m}\right)_{0}-\left(p_{f}\right)_{0}\right] . }
\end{aligned}
$$


If the sexual preference is determined by a locus linked to the $\mathrm{X}$-chromosome but the A-B locus is not sex-linked, then although the two loci will segregate independently the sexual preference will still become associated with the advantageous male genotype and selection of the sexual preference will take place in the way Fisher suggests. In the $n$th generation let the genotypes have the frequencies as follows:

\begin{tabular}{lclc}
\multicolumn{2}{c}{ Females } & \multicolumn{2}{c}{ Males } \\
Genotype & Frequency & Genotype & Frequency \\
$\mathrm{AAX}^{\alpha} \mathrm{Y}$ & $x$ & $\mathrm{AAX}^{\alpha} \mathrm{X}^{\alpha}$ & $h$ \\
$\mathrm{ABX}^{\alpha} \mathrm{Y}$ & $y$ & $\mathrm{ABX}^{\alpha} \mathrm{X}^{\alpha}$ & $i$ \\
$\mathrm{BBX}^{\alpha} \mathrm{Y}$ & $z$ & $\mathrm{BBX}^{\alpha} \mathrm{X}^{\alpha}$ & $j$ \\
$\mathrm{AAX}^{+} \mathrm{Y}$ & $r$ & $\mathrm{AAX}^{\alpha} \mathrm{X}^{+}$ & $k$ \\
$\mathrm{ABX}^{+} \mathrm{Y}$ & $s$ & $\mathrm{ABX}^{\alpha} \mathrm{X}^{+}$ & $l$ \\
$\mathrm{BBX}^{+} \mathrm{Y}$ & $t$ & $\mathrm{BBX}^{\alpha} \mathrm{X}^{+}$ & $m$ \\
Total & $\mathrm{I}$ & $\mathrm{AAX}^{+} \mathrm{X}^{+}$ & $n$ \\
& & $\mathrm{ABX}^{+} \mathrm{X}^{+}$ & $p$ \\
& & $\mathrm{BBX}^{+} \mathrm{X}^{+}$ & $q$ \\
& & Total & I
\end{tabular}

As in the basic model $\mathrm{X}^{\alpha} \mathrm{Y}$ females mate only with AA males. These matings give the following nine mating types:

$\begin{array}{lc}\quad \text { Mating Type } & \text { Frequency } \\ \operatorname{AAX}^{\alpha} \mathrm{X}^{\alpha} \times \mathrm{AAX}^{\alpha} \mathrm{Y} & h x \\ \mathrm{AAX}^{\alpha} \mathrm{X}^{\alpha} \times \mathrm{ABX}^{\alpha} \mathrm{Y} & h y \\ \mathrm{AAX}^{\alpha} \mathrm{X}^{\alpha} \times \mathrm{BBX}^{\alpha} \mathrm{Y} & h z \\ \mathrm{AAX}^{\alpha} \mathrm{X}^{+} \times \mathrm{AAX}^{\alpha} \mathrm{Y} & k x \\ \mathrm{AAX}^{\alpha} \mathrm{X}^{+} \times \mathrm{ABX}^{\alpha} \mathrm{Y} & k y \\ \mathrm{AAX}^{\alpha} \mathrm{X}^{+} \times \mathrm{BBX}^{\alpha} \mathrm{Y} & k z \\ \mathrm{AAX}^{+} \mathrm{X}^{+} \times \mathrm{AAX}^{\alpha} \mathrm{Y} & n x \\ \mathrm{AAX}^{+} \mathrm{X}^{+} \times \mathrm{ABX}^{\alpha} \mathrm{Y} & n y \\ \mathrm{AAX}^{+} \mathrm{X}^{+} \times \mathrm{BBX}^{\alpha} \mathrm{Y} & n z\end{array}$

Divisor: $h+k+n$

The remaining females mate at random with the males. There are twenty-seven mating types with the frequencies shown in the table:

$\begin{array}{ccccc} & & \text { Females } & \\ & & \mathrm{AAX}^{+} \mathrm{Y} & \mathrm{ABX}+\mathrm{Y} & \mathrm{BBX}+\mathrm{Y} \\ & \mathrm{AAX}^{\alpha} \mathrm{X}^{\alpha} & h r & h s & h t \\ \mathrm{ABX}^{\alpha} \mathrm{X}^{\alpha} & i r & i s & i t \\ \mathrm{BBX}^{\alpha} \mathrm{X}^{\alpha} & j r & j s & j t \\ \mathrm{AAX}^{\alpha} \mathrm{X}^{+} & k r & k s & k t \\ & \mathrm{ABX}^{\alpha} \mathrm{X}^{+} & l r & l s & l t \\ \mathrm{BBX}^{\alpha} \mathrm{X}^{+} & m r & m s & m t \\ \mathrm{AAX}^{+} \mathrm{X}^{+} & n r & n s & n t \\ & \mathrm{ABX}^{+} \mathrm{X}^{+} & p r & p s & p t \\ & \mathrm{BBX}^{+} \mathrm{X}^{+} & q r & q s & q t\end{array}$


In the following generation the genotypic frequencies will have become

$$
\begin{aligned}
x^{\prime} & =\left(x+\frac{1}{2} y\right)\left(h+\frac{1}{2} k\right) /(h+k+n)+\left(r+\frac{1}{2} s\right)\left(h+\frac{1}{2} i+\frac{1}{2} k+\frac{1}{4} l\right) \\
y^{\prime} & =\left(z+\frac{1}{2} y\right)\left(h+\frac{1}{2} k\right) /(h+k+n)+\left(r+\frac{1}{2} s\right)\left(j+\frac{1}{2} i+\frac{1}{2} m+\frac{1}{4} l\right) \\
z^{\prime} & +\left(t+\frac{1}{2} s\right)\left(h+\frac{1}{2} i+\frac{1}{2} k+\frac{1}{4} l\right) \\
r^{\prime} & =\left(x+\frac{1}{2} i+\frac{1}{2} m+\frac{1}{2} l\right)\left(n+\frac{1}{2} k\right) /(h+k+n)+\left(r+\frac{1}{2} s\right)\left(n+\frac{1}{2} p+\frac{1}{2} k+\frac{1}{4} l\right) \\
s^{\prime} & =\left(z+\frac{1}{2} y\right)\left(n+\frac{1}{2} k\right) /(h+k+n)+\left(r+\frac{1}{2} s\right)\left(q+\frac{1}{2} p+\frac{1}{2} m+\frac{1}{4} l\right) \\
t^{\prime} & =\left(t+\frac{1}{2} s\right)\left(q+\frac{1}{2} p+\frac{1}{2} m+\frac{1}{2} l\right) \\
h^{\prime} & =\left(x+\frac{1}{2} y\right)\left(h+\frac{1}{2} k\right) /(h+k+n) \\
i^{\prime} & =\left(z+\frac{1}{2} y\right)\left(h+\frac{1}{2} k\right) /(h+k+n) \\
j^{\prime} & =0 \\
k^{\prime} & =\left(x+\frac{1}{2} y\right)\left(n+\frac{1}{2} k\right) /(h+k+n)+\left(r+\frac{1}{2} s\right)\left(h+\frac{1}{2} i+\frac{1}{2} k+\frac{1}{4} l\right) \\
l^{\prime} & =\left(z+\frac{1}{2} y\right)\left(n+\frac{1}{2} k\right) /(h+k+n)+\left(r+\frac{1}{2} s\right)\left(j+\frac{1}{2} i+\frac{1}{2} m+\frac{1}{4} l\right) \\
m^{\prime} & =\left(t+\frac{1}{2} s\right)\left(j+\frac{1}{2} i+\frac{1}{2} m+\frac{1}{4} l\right) \\
n^{\prime} & =\left(r+\frac{1}{2} s\right)\left(n+\frac{1}{2} p+\frac{1}{2} k+\frac{1}{4} l\right) \\
p^{\prime} & =\left(r+\frac{1}{2} s\right)\left(q+\frac{1}{2} p+\frac{1}{2} m+\frac{1}{4} l\right)+\left(t+\frac{1}{2} s\right)\left(n+\frac{1}{2} p+\frac{1}{2} k+\frac{1}{4} l\right) \\
q^{\prime} & =\left(t+\frac{1}{2} s\right)\left(q+\frac{1}{2} p+\frac{1}{2} m+\frac{1}{4} l\right)
\end{aligned}
$$

Let $u_{f}, v_{f}$ and $w_{f}$ be the frequencies in the females of the genotypes $\mathrm{AA}, \mathrm{AB}$ and $\mathrm{BB}$, and $u_{m}, v_{m}$ and $w_{m}$ be the corresponding frequencies in the males. Then we have

and

$$
\begin{gathered}
u_{f}=x+r \\
v_{f}=y+s \\
w_{f}=z+t
\end{gathered}
$$

$$
\begin{aligned}
u_{m} & =h+k+n \\
v_{m} & =i+l+p \\
w_{m} & =j+m+q .
\end{aligned}
$$

Thus in the following generation these frequencies become

and

$$
\begin{aligned}
& u_{f^{\prime}}^{\prime}=\left(x+\frac{1}{2} y\right)+\left(r+\frac{1}{2} s\right)\left(u_{m}+\frac{1}{2} v_{m}\right) \\
& v_{f}^{\prime}=\left(z+\frac{1}{2} y\right)+\left(r+\frac{1}{2} s\right)\left(w_{m}+\frac{1}{2} v_{m}\right)+\left(t+\frac{1}{2} s\right)\left(u_{m}+\frac{1}{2} v_{m}\right)
\end{aligned}
$$

$$
\begin{aligned}
& u_{m}{ }^{\prime}=\left(x+\frac{1}{2} y\right)+\left(r+\frac{1}{2} s\right)\left(u_{m}+\frac{1}{2} v_{m}\right) \\
& v_{m}{ }^{\prime}=\left(z+\frac{1}{2} y\right)+\left(r+\frac{1}{2} s\right)\left(w_{m}+\frac{1}{2} v_{m}\right)+\left(t+\frac{1}{2} s\right)\left(u_{m}+\frac{1}{2} v_{m}\right) .
\end{aligned}
$$

The frequencies of the genotypes $\mathrm{AA}, \mathrm{AB}$ and $\mathrm{BB}$ are therefore the same in both males and females and the suffixes may be dropped. This gives

$$
\begin{aligned}
& u^{\prime}=\left(x+\frac{1}{2} y\right)\left(w+\frac{1}{2} v\right)+\left(u+\frac{1}{2} v\right)^{2} \\
& v^{\prime}=\left(z+\frac{1}{2} y\right)\left(w+\frac{1}{2} v\right)-\left(x+\frac{1}{2} y\right)\left(w+\frac{1}{2} v\right)+2\left(u+\frac{1}{2} v\right)\left(w+\frac{1}{2} v\right) .
\end{aligned}
$$

But $x+y+z=\alpha$ so that $x+\frac{1}{2} y=\alpha-\left(z+\frac{1}{2} y\right)$ whence we have

$$
v^{\prime}=2\left(z+\frac{1}{2} y\right)\left(w+\frac{1}{2} v\right)-\alpha\left(w+\frac{1}{2} v\right)+2\left(u+\frac{1}{2} v\right)\left(w+\frac{1}{2} v\right) .
$$


If we now let $p$ and $q$ be the frequencies of the alleles A and B

which gives

$$
p^{\prime}=\frac{1}{2} \alpha q+p
$$

$$
p^{\prime}=\left(1-\frac{1}{2} \alpha\right) p+\frac{1}{2} \alpha .
$$

This recurrence relation cannot, of course, be applied directly for $\alpha$ no longer remains constant from generation to generation. The recurrence relation does show, however, that in the final state of equilibrium the population will consist only of AA genotypes. This means that at equilibrium

and

$$
\begin{aligned}
x+r & =\mathrm{I} \\
h+k+n & =\mathrm{I}
\end{aligned}
$$

$$
\begin{aligned}
& x=x\left(h+\frac{1}{2} k\right)+r\left(h+\frac{1}{2} k\right)=\left(h+\frac{1}{2} k\right) \\
& r=x\left(n+\frac{1}{2} k\right)+r\left(n+\frac{1}{2} k\right)=\left(n+\frac{1}{2} k\right) \\
& h=x\left(h+\frac{1}{2} k\right) \\
& k=x\left(n+\frac{1}{2} k\right)+r\left(h+\frac{1}{2} k\right) \\
& n=r\left(n+\frac{1}{2} k\right)
\end{aligned}
$$

Unfortunately these equations do not give the equilibrium values for $x, r, h, k$ and $n$; but since $x=h+\frac{1}{2} k$, they do show that at equilibrium

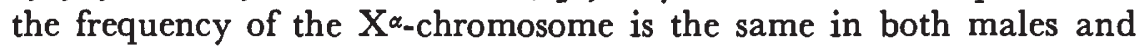
females. In general, however, it is necessary to obtain recurrence relations for $\alpha_{f}$ and $\alpha_{m}$ where thesevalues are respectively the frequencies of the $\mathrm{X}^{\alpha}$-chromosome in females and in males. We have

$$
\begin{aligned}
\alpha_{f}^{\prime} & =x^{\prime}+y^{\prime}+z^{\prime} \\
& =\alpha_{f}\left(h+\frac{1}{2} k\right) /(h+k+n)+\left(1-\alpha_{f}\right)\left(h+\frac{1}{2} i+\frac{1}{2} k+\frac{1}{4} l\right) \\
\alpha_{m}{ }^{\prime} & =h^{\prime}+i^{\prime}+j^{\prime}+\frac{1}{2} k^{\prime}+\frac{1}{2} l^{\prime}+\frac{1}{2} m^{\prime} \\
& =\alpha_{f}\left(h+\frac{1}{2} k\right) /(h+k+n)\left(j+\frac{1}{2} i+\frac{1}{2} m+\frac{1}{4} l\right)
\end{aligned}
$$

Thus

$$
\begin{aligned}
& \alpha_{f}^{\prime}=\alpha_{f}\left(h+\frac{1}{2} k\right) / u+\alpha_{m}\left(1-\alpha_{f}\right) \\
& \alpha_{m}{ }^{\prime}=\alpha_{f}\left(h+\frac{1}{2} k\right) / u+\frac{1}{2} \alpha_{f}\left(n+\frac{1}{2} k\right) / u+\frac{1}{2} \alpha_{m}\left(1-\alpha_{f}\right)
\end{aligned}
$$

When $h$ is put equal to $u$, these equations reduce to those already obtained for the case of the A allele closely linked to $\alpha$.

At equilibrium we have proved that $\alpha_{f}=\alpha_{m}$, so that dropping the suffixes we have

Thus near equilibrium

$$
\alpha^{\prime}=\alpha^{2}+\alpha(1-\alpha) \text {. }
$$

$$
\alpha^{\prime} \simeq \alpha
$$

and the rate of selection will approximate to that in which no selection of the female preference takes place. This is the case of the Y-linked preference which has already been described in detail. 
If initially the frequency of the $\mathrm{X}^{\alpha}$-chromosome is very low so that $h$ and $k$ are negligible, then we have

or

$$
\begin{aligned}
& \alpha_{f}^{\prime} \simeq \alpha_{m} \\
& \alpha_{m}{ }^{\prime} \simeq \frac{1}{2} \alpha_{f}+\frac{1}{2} \alpha_{m}
\end{aligned}
$$

$\alpha^{\prime} \simeq \alpha$.

Thus again the rate of selection is similar to that in the Y-linked case. To study the rate of selection between the two extremes, however, an extensive computation is needed involving repeated application of the fifteen basic recurrence relations. This must be left until an electronic computer can be programmed to make the calculations. But it has been shown, at least near the initial and final states, that selection of the female preference of the type postulated by Fisher will have only a slight effect on the rate of sexual selection. This will not be strictly true in nature, for the male characteristics and the system of female preference will both be determined by a number of alleles at several loci; and, as these become associated with one another, so also will the selective effect be enhanced.

What does appear clearly, however, is the effect of linkage which will increase the rate of selection. Any mutation that enhances the female preference and that is also linked to a sexually advantageous gene will immediately be picked out by selection; the closer the linkage the more rapidly will the advantageous combination advance; and any factor that tightens the linkage will also be selected. Favourable combinations of closely-linked factors, or supergenes, should therefore evolve under sexual selection. Thus we should expect to find that one or more supergenes control both male display and the female response to it.

\section{CONCLUSIONS}

On the basis of these arguments, we may conclude that sexual selection may well have been of profound importance in the evolution of higher organisms. In its later stages, as Fisher noted, it may be expected to produce great effects with great rapidity. In most species at present in existence, however, the opposing pressures of natural selection must have already halted the runaway process, for the great rapidity with which sexual selection can act makes it unlikely to be observed in progress at any one time. Finally in man, we may note, with Darwin, who quotes many examples, the tendency to exaggerate each natural peculiarity. Thus Darwin suggests that as the members of a tribe split up into separate districts " the hordes would thus be exposed to slightly different conditions and habits of life, and would sooner or later come to differ in some small degree. As soon as this occurred, each isolated tribe would form for itself a slightly different standard of beauty; and then unconscious selection would come into action through the more powerful and leading men preferring certain women to others. Thus the differences between the tribes, at first very 
slight, would gradually and inevitably be more or less increased." Selection of the men by the women would also take place and so the racial differences in man could well have been enhanced by sexual selection.

\section{SUMMARY}

I. Darwin's theory of sexual selection is discussed in the light of Fisher's theory of the evolution of sexual preferences. Females who prefer to mate with males favoured in natural selection will themselves gain an advantage from the advantage which on average their sons will possess. This advantage will be further increased as a result of the female preference for these sons.

2. Mathematical models are developed for two basic situations: in the first, a constant sexual preference is assumed in all females; in the second, the gene that determines the female preference is selected through Fisher's process.

3. The rate of selection of the gene for the female preference will be quick when this gene is linked to the gene that determines the advantageous male genotype. The evolution of a linked complex will be extremely rapid. Thus it seems likely that one or more supergenes will control both male display and the female response to it.

Acknowledgment.-The author gratefully acknowledges the receipt of a Nature Conservancy Research Studentship during part of this work.

\section{REFERENCES}

сотт, н. в. 1954. Allæsthetic selection and its evolutionary aspects, in Huxley, J. S. et al., Evolution as a Process, George Allen and Unwin, London.

Darwin, Gharles. 1859. On the Origin of Species by Means of Natural Selection. John Murray, London.

Darwin, Charles. 1871. The Descent of Man and Selection in Relation to Sex. John Murray, London.

FISHER, R. A. 1930. The Genetical Theory of Natural Selection. Clarendon Press, Oxford.

HUXLEY, J. s. 1938. The present standing of the theory of sexual selection, in de Beer, G. R., Evolution, Clarendon Press, Oxford.

MAther, K. I 955 . Polymorphism as an outcome of disruptive selection. Evolution, 9, 52-6I.

maynard-smith, J. 1958. Sexual selection, in Barnett, S. A., A Century of Darwin, Heinemann, London.

MOTTRAM, J. C. 1915. The distribution of secondary sexual characters amongst birds, with relation to their liability to the attack of enemies. Proc. Zool. Soc. London, $663-678$. 